\title{
Preliminary immunological studies in search of correlates of protective immunity carried out on some Iranian leprosy patients and their families
}

\author{
J L STANFORD, * G A W ROOK, * N SAMUEL, * \\ F MADLENER,${ }^{\dagger}$ A A KHAMENEI, ${ }^{\dagger}$ T NEMATI,$\dagger$ \\ F MODABBER $\$$ \& R J W REES** \\ * School of Pathology, Middlesex Hospital Medical School, \\ Riding House Street, London W1; †Baba Baghi Leprosy Sana- \\ torium, Tabriz, Iran; \$School of Public Health, University of \\ Teheran, Teheran; **National Institute for Medical Research, \\ Mill Hill, London
}

\section{Received for publication 26 April 1980}

Summary Multiple skin-testing, lymphocyte transformation tests and enzyme-linked immunosorbent assay of antibodies to mycobacterial antigens have been carried out on patients and their healthy children living in Baba Baghi Leprosy Sanatorium in Iran. The data reported shows a remarkable correlation between responses to Mycobacterium leprae and $M$. vaccae in all 3 test systems.

The percentage of positive responders to skin tests with Leprosin A amongst the children is higher than has previously been found and BCG has been shown to enhance the capacity of the individual to recognize $M$. leprae in this way. Finally, the majority of a small number of children considered to be protected from leprosy have been shown to possess lymphocytes that transform in the presence of $M$. leprae and $M$. vaccae antigens, but little antibody to $M$. leprae by the enzyme-linked immunosorbent assay. Of the 3 types of test assessed here only skin-testing appears to be of any value as a measure of protection, but whether even this will prove useful at the individual level is far from certain.

\section{Introduction}

The purpose of this study was to evaluate 3 tests as correlates of protection from mycobacterial disease. It was carried out at Baba Baghi Leprosy Sanatorium near Tabriz in Iranian Azerbaijan. None of the children born and 
brought up in the Sanatorium have developed leprosy in the 20 years that families have lived there, despite their frequent contact with new bacilliferous patients and a marked tendency amongst a few of the patients not to take their drugs. The majority of the children must therefore have protective immunity since most are in daily contact with bacilliferous cases of the disease. Since it is not possible to define a control group without protection we make a comparison between healthy children and the patients with whom they live. Of the 47 families living at Baba Baghi, 45 agreed to take part. Each person was skin tested and subsequently blood samples were obtained from individuals selected on the basis of skin-test results. These were used for lymphocyte transformation studies and enzyme-linked immunosorbent assay of antibodies.

\section{Materials and methods}

\section{THE FAMILIES}

Forty-two of the families consisted of leprous parents and from 1 to 5 healthy children. One family consisted of the husband and 2 wives, all with leprosy and 3 healthy children. Two families consisted of a mother with leprosy, each with a single healthy child.

A grandfather lived with one of the families, an uncle with another family and an uncle and aunt with a third family. In each case these extra family members had leprosy. One of the healthy children was herself married to a leprosy patient.

Apart from a few children who were staying with relatives away from the Sanatorium or who had got married and left, and one child who went on holiday before the skin tests were read, every family member was skin tested. Some of the children had accompanied parents from their village when they first came to the Sanatorium, but most were born in the Sanatorium and had spent all their lives there. The total number of parents and other relatives studied was 94 and the total number of children studied was 113. (Additionally some skin-test results for other patients in the leprosarium have been added to Table 1.)

\section{SKIN TESTS}

The reagents used were a range of new tuberculins prepared from live organisms grown on Sauton's agar, or, in the case of Leprosin A, from irradiated organisms harvested from armadillo tissues and freed from material of armadillo origin by the method of Draper (in Shepard et al., 1980). In each case the harvested organisms were broken with ultrasound. The sonicates were sterilized by serial filtration, the protein content measured, and the final dilutions 
Table 1. The results of skin-testing leprosy patients and their children with a series of new tuberculins

\begin{tabular}{lcccc}
\hline \multicolumn{1}{c}{ Reagent } & Concentration & Patients + ve & Children + ve & $\begin{array}{c}\text { Significance } \\
\left(\text { Chi }^{2}\right)\end{array}$ \\
\hline Leprosin A & $10 \mu \mathrm{g} / \mathrm{ml}$ & $18 / 127$ & $71 / 113$ & $P<0.0001$ \\
Vaccin & $20 \mu \mathrm{g} / \mathrm{ml}$ & $3 / 58$ & $16 / 24$ & $P<0.0001$ \\
Nonchromogenicin & $20 \mu \mathrm{g} / \mathrm{ml}$ & $17 / 43$ & $18 / 25$ & $P<0.01$ \\
Scrofulin & $2 \mu \mathrm{g} / \mathrm{ml}$ & $21 / 48$ & $12 / 24$ & $\mathrm{~ns}$ \\
Xenopin & $2 \mu \mathrm{g} / \mathrm{ml}$ & $2 / 31$ & $5 / 25$ & $\mathrm{~ns}$ \\
Rhodesin & $2 \mu \mathrm{g} / \mathrm{ml}$ & $0 / 19$ & $6 / 25$ & $\mathrm{~ns}$ \\
Marinin & $2 \mu \mathrm{g} / \mathrm{ml}$ & $28 / 40$ & $19 / 25$ & \\
Diernhoferin & $2 \mu \mathrm{g} / \mathrm{ml}$ & $0 / 7$ & $0 / 4$ & \\
Neoaurumin & $2 \mu \mathrm{g} / \mathrm{ml}$ & $0 / 6$ & $3 / 8$ & \\
Gilvin & $2 \mu \mathrm{g} / \mathrm{ml}$ & $1 / 6$ & $3 / 4$ & \\
Duvalin & $2 \mu \mathrm{g} / \mathrm{ml}$ & $0 / 6$ & $2 / 4$ & \\
A*-in & $2 \mu \mathrm{g} / \mathrm{ml}$ & $10 / 19$ & $4 / 5$ & \\
Aviumin C & $2 \mu \mathrm{g} / \mathrm{ml}$ & $2 / 7$ & $1 / 5$ & $\mathrm{~ns}$ \\
Gordonin & $2 \mu \mathrm{g} / \mathrm{ml}$ & $9 / 21$ & $3 / 5$ & \\
Chitin & $2 \mu \mathrm{g} / \mathrm{ml}$ & $2 / 6$ & $2 / 7$ & \\
Skinsnes'reagent & $2 \mu \mathrm{g} / \mathrm{ml}$ & $13 / 39$ & $19 / 31$ & \\
ICRC reagents & $2 \mu \mathrm{g} / \mathrm{ml}$ & $5 / 12$ & $10 / 15$ & \\
Kanasin & $2 \mu \mathrm{g} / \mathrm{ml}$ & $17 / 26$ & - & \\
Aviumin A & $2 \mu \mathrm{g} / \mathrm{ml}$ & $3 / 12$ & - & \\
\hline
\end{tabular}

In this table + ve refers to responses of $2 \mathrm{~mm}$ or more of induration to the skin-test reagents shown.

prepared in a tween containing borate buffer containing tween (Paul et al., 1975). The concentrations used for skin testing were $20 \mu \mathrm{g} / \mathrm{ml}$ in the cases of Vaccin and Non-chromogenicin, $10 \mu \mathrm{g} / \mathrm{ml}$ in the case of Leprosin A, and $2 \mu \mathrm{g} / \mathrm{ml}$ for all the other reagents.

Every person was skin tested by the intradermal injection of $1 \mu \mathrm{g}$ of Leprosin A and all but 11 of the youngest children (aged 1-3 years) were skin tested with 2 or 3 other reagents at the same time. Reactions were recorded as mean diameters of induration at 72 hours and reactions of $2 \mathrm{~mm}$ or more were considered positive. The list of reagents, numbers tested and numbers producing positive responses are shown in Table 1.

Ninety-two of the children had received BCG vaccination, a number of them on several occasions. This was confirmed by examination of their arms for scars. The distribution of the children by age, BCG status and response to Leprosin A is shown in Table 2.

\section{IN VITRO TESTS}

Blood samples were taken from 23 carefully selected children. Fourteen children who did not respond to skin test with Leprosin A agreed to be bled and in 9 cases there was a suitable Leprosin A-positive brother or sister who 
Table 2. The effect of BCG and age on positivity to skin tests with Leprosin $A$

\begin{tabular}{|c|c|c|c|}
\hline Age & $\begin{array}{c}\text { BCG }- \text { ve } \\
\text { Leprosin } A+v e\end{array}$ & \multicolumn{2}{|c|}{$\begin{array}{c}\text { BCG }+v e \\
\text { Leprosin } A+v e\end{array}$} \\
\hline \multicolumn{4}{|c|}{ (A) Baba Baghi children } \\
\hline 1 & $0 / 8$ & & \\
\hline 2 & $0 / 6$ & $3 / 4$ & \\
\hline 3 & $0 / 3$ & $1 / 3$ & \\
\hline 4 & & $3 / 6$ & \\
\hline 5 & $0 / 1$ & $2 / 5$ & \\
\hline 6 & & $0 / 4$ & \\
\hline 7 & & $2 / 3$ & $11 / 25(44 \%)$ \\
\hline 8 & & $2 / 2$ & \\
\hline 9 & $0 / 1$ & $5 / 7$ & \\
\hline 10 & $1 / 1$ & $10 / 11$ & \\
\hline 11 & & $10 / 12$ & \\
\hline 12 & & $7 / 8$ & $34 / 40(85 \%)$ \\
\hline 13 & $0 / 1$ & $7 / 7$ & \\
\hline 14 & & $6 / 6$ & \\
\hline 15 & & $6 / 8$ & \\
\hline 16 & & $4 / 4$ & \\
\hline 17 & & $1 / 1$ & \\
\hline \multicolumn{4}{|l|}{18} \\
\hline \multicolumn{4}{|l|}{19} \\
\hline \multirow[t]{2}{*}{20} & & $1 / 1$ & $25 / 27(93 \%)$ \\
\hline & $1 / 21(4.8 \%)$ & \multicolumn{2}{|c|}{$70 / 92(76 \%)$} \\
\hline
\end{tabular}

(B) Children living in a town in the leprosy endemic area

\begin{tabular}{lll}
12 & $4 / 9$ & $13 / 24$ \\
13 & $3 / 14$ & $9 / 27$ \\
14 & $2 / 9$ & $16 / 26$ \\
& $9 / 32(28 \%)$ & $38 / 77(49 \%)$ \\
\hline
\end{tabular}

$\mathrm{BCG}+\mathrm{ve}$ and - ve refer to vaccinated and nonvaccinated children respectively. Leprosin A + ve refers to children producing induration of $2 \mathrm{~mm}$ diameter or more to this reagent.

also agreed to be bled. As far as possible pairs from each family were of the same sex, roughly the same age and with the same BCG status. Five children were either single or had brothers or sisters too young to be bled for comparison. In every case the children came from families with at least one lepromatous parent. Blood samples were collected from 27 male leprosy patients (mainly lepromatous) for comparison with the children.

Lymphocyte transformation tests were carried out on cells separated with methyl cellulose in a system suitable for simple laboratory conditions as described by Rook and Stanford (in preparation). Cells were cultured in 
RPM 1 medium in the presence of $10 \%$ autologous serum. Leprosin A, Vaccin, Tuberculin and Nonchromogenicin were used as antigens at a final concentration of $20 \mu \mathrm{g} / \mathrm{ml}$.

\section{ENZYME-LINKED IMMUNOSORBENT ASSAY}

This assay was performed as described by Voller et al. (1979) using peroxidase conjugated rabbit antisera to human immunoglobulin heavy chains (Dako). The antigens were the preparations used for skin-testing, diluted to $1 \mu \mathrm{g} / \mathrm{ml}$ and all sera were tested at a dilution of $1 / 800$. The substrate was O-phenylene diamine. Data are presented as geometric means of absorbance values and statistical analysis was performed using log.-transformed absorbance values and Student's t test.

\section{Results}

\section{SKIN TESTS}

The results of all skin tests carried out on the patients and their children are shown in Table 1 and the significance of differences between results for the 2 groups are also indicated $\left(\mathrm{Chi}^{2}\right)$.

From Table 2 it can be seen that BCG has a considerable effect on development of Leprosin A positivity and so too does age. Thus of 21 children who had not received $\mathrm{BCG}$ only 1 was Leprosin A positive and of $92 \mathrm{BCG}$ recipients 70 were positive. Among the BCG recipients, of the 25 aged 7 or less, 11 were Leprosin A positive, of the 40 aged 8-12, 34 were positive and of the 27 aged 13-20, 25 were positive. These results and the corresponding figures for Nonchromogenicin and Vaccin tests are shown together with the results obtained on the leprosy patients themselves in Table 3.

Table 3. The effect of age on response to 3 skin-test reagents in children who had received BCG. The results obtained in leprosy patients are shown for comparison

\begin{tabular}{cllcc}
\hline & \multicolumn{3}{c}{ Positive responders to } \\
\cline { 3 - 5 } & & Leprosin A & Vaccin & Nonchromogenicin \\
Patients & & $13 / 94(14 \%)$ & $1 / 17(6 \%)$ & $5 / 19(26 \%)$ \\
\hline BCG + ve, Children aged: & $2-7$ & $11 / 25(44 \%)$ & $1 / 5(20 \%)$ & $1 / 1$ \\
& $8-12$ & $34 / 40(85 \%)$ & $9 / 11(82 \%)$ & $7 / 12(58 \%)$ \\
& $13-20$ & $25 / 27(93 \%)$ & $6 / 7(86 \%)$ & $8 / 8(100 \%)$ \\
\hline
\end{tabular}

Mycobacterium nonchromogenicum and $M$. vaccae were the two species shown to be related to the leprosy bacillus in skin-test studies in East Africa by Paul et al. (1975), and $M$ vaccae was the species most similar to $M$. leprae in some taxonomic studies (Stanford et al., 1975; 1978). The sizes in millimetres 
of responses of the children to Leprosin A are shown in Figure 1. Table 5 shows the mean positive reaction sizes to 5 reagents for patients and their BCGvaccinated children. Statistical differences determined by Student's t test are indicated.

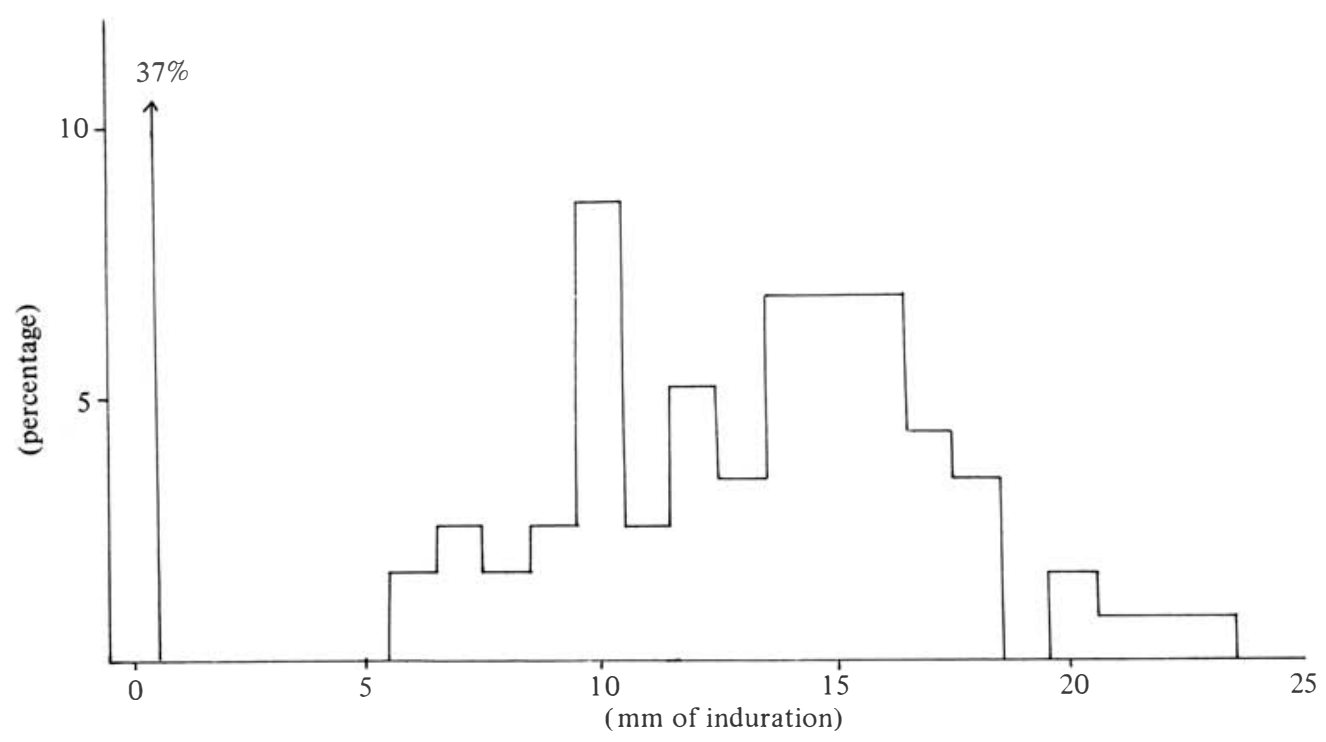

Figure 1. The percentages of children producing responses to Leprosin A expressed as millimetres of induration at 72 hours.

\section{IN VITRO TESTS}

The results of the lymphocyte transformation tests are shown in Figure 2 as ratios of uptake of radioactive thymidine by cultures in the presence of antigen and in its absence. The results for Leprosin A skin-test responders (LA + ve) and non-responders (LA - ve) are shown separately.

\section{ENZYME-LINKED IMMUNOSORBENT ASSAY}

Patients showed very significantly more $\operatorname{IgG}$ antibody to $M$. leprae and $M$. vaccae than either the Leprosin A - ve or the Leprosin A + ve children (Table 6). However, they did not have significantly more antibody than the Leprosin $\mathrm{A}+$ ve children, to $M$. nonchromogenicum or M. tuberculosis. There was also a tendency, not always significant, for Leprosin A + ve children to have less antibody to $M$. leprae and $M$. vaccae and more antibody to $M$. nonchromogenicum and $M$. tuberculosis, than the Leprosin A - ve children. 


\section{Discussion}

The overall percentage of positive responders to Leprosin A of $64 \%$ among the 113 children tested is the highest recorded so far with this reagent. Among the 92 children vaccinated with BCG $76 \%$ responded to Leprosin A. This association of Leprosin A positivity with BCG vaccination could be explained in one of two ways. Either there is marked cross-reaction between Leprosin and BCG or BCG enhances the individuals capacity to recognize Mycobacterium leprae met in the environment. Of these two alternatives the latter is likely to be the true explanation. This is shown in Table 2 by the effect of age on skin-test responses among the BCG recipients. Although not tabulated this same age effect among the BCG recipients is seen for each of the reagents to which a resonable proportion of the children respond, and has been documented in previous studies (Paul et al., 1975; Stanford et al., 1976; Shield et al., 1977; Stanford et al., 1980). However, the effect is not seen with reagents prepared from mycobacterial species absent from the child's environment indicating that it is not cross-reactivity that increases with time after BCG vaccination. Recipients of the same BCG, aged 12-14 and still living in the region from which most of the patients originated, are much less responsive (49\% positive) to Leprosin A than are the children reported here, (see the lower section of Table 2 ). Thus, in an environment where the leprosy bacillus is frequently encountered, BCG administration markedly enhances immunological recognition resulting in development of positivity to Leprosin A. That this is beneficial is suggested by the rarity of leprosy developing in these children. Thus to this extent positivity to skin-testing with Leprosin A is a measure of protection.

Unfortunately this is not likely to be the whole story, if it were then BCG vaccination might be expected to be effective against leprosy everywhere the disease is common. That other organisms are involved in the process of recognition of $M$. leprae was suggested by our earlier studies (Paul et al., 1975) and has been supported by much as yet unpublished data from the field and from animal experiments.

Correlations between the results of testing with Leprosin A and with some of the other test reagents can be made. These are shown in Table 4 under two categories. The total correlations including failures to respond to both reagents and positive responses to both reagents. Positive correlations are also shown in which persons producing positive reactions to pairs of reagents are expressed as a percentage of all persons responding to at least one of the pair. Because too few persons were tested with some of the reagents for meaningful correlations to be derived the results have been pooled. 'Fast growers' include the results for Diernhoferin, Neoaurumin, Gilvin, Duvalin and Chitin; 'Slow growers' include $A^{*}$-in (made from an as yet unnamed species), Aviumin $\mathrm{C}$ and Gordonin. The reagents prepared from 9 of Professor Skinsnes' strains grown from leprosy patients fall into 2 clusters, a group of 6 reagents showing little correlation 
Table 4. The relationships between skin-test responses to Leprosin A and to the other reagents tested. See text for an explanation of the correlations shown

\begin{tabular}{lcccc}
\hline & & & \multicolumn{2}{c}{ Correlations } \\
\cline { 4 - 5 } \multicolumn{1}{c}{ 'Other' reagent } & Leprosin A + ve & 'Other' reagent + ve & Total & Positve \\
\hline Vaccin & $19 / 41$ & $17 / 41$ & $39 / 41(95 \%)$ & $17 / 19(89 \%)$ \\
Nonchromogenicin & $22 / 44$ & $22 / 44$ & $33 / 44(75 \%)$ & $17 / 27(63 \%)$ \\
Marinin & $23 / 51$ & $37 / 51$ & $34 / 51(67 \%)$ & $22 / 38(58 \%)$ \\
ICRC 1204 & $15 / 27$ & $13 / 27$ & $21 / 27(78 \%)$ & $10 / 18(56 \%)$ \\
ICRC 1203 & $15 / 27$ & $9 / 27$ & $20 / 27(74 \%)$ & $8 / 16(50 \%)$ \\
Skinsnes $\times 6$ & $26 / 92$ & $8 / 92$ & $64 / 92(70 \%)$ & $2 / 32(6 \%)$ \\
Skinsnes $\times 3$ & $20 / 38$ & $14 / 38$ & $32 / 38(84 \%)$ & $14 / 20(70 \%)$ \\
Fast growers & $16 / 46$ & $11 / 46$ & $37 / 46(80 \%)$ & $9 / 18(50 \%)$ \\
Slow growers & $9 / 36$ & $14 / 36$ & $29 / 36(81 \%)$ & $7 / 16(44 \%)$ \\
Scrofulin & $19 / 41$ & $16 / 41$ & $30 / 41(73 \%)$ & $12 / 23(52 \%)$ \\
Rhodesin & $22 / 44$ & $6 / 44$ & $27 / 44(61 \%)$ & $6 / 22(27 \%)$ \\
Xenopin & $22 / 44$ & $6 / 44$ & $25 / 44(57 \%)$ & $4 / 24(17 \%)$ \\
\hline
\end{tabular}

with Leprosin A and a group of 3 reagents showing much better correlation. Much the best correlation is shown by $M$. vaccae which appears to have some special relationship with $M$. leprae. Of the 17 individuals producing positive responses to Vaccin all produced positive responses to Leprosin A, although there were 2 responders to Leprosin A who did not respond to Vaccin. Thus positivity to Vaccin may also be a measure of protection from infection. Other species also show a correlation with Leprosin A, although to a much smaller extent. It is interesting to note that reagents prepared from 3 of Professor Skinsnes' isolates from leprosy tissues show $70 \%$ of positive correlation with Leprosin A. More results are needed with these strains to confirm this particularly since the concentration of reagents used may not have been optimal. The nature of the relationships reflected by correlations of skin-test results is not clear and again simple cross-reactivity does not appear to be the explanation. In unpublished experiments on mice, Vaccin positivity can be shown to enhance the animals capacity to develop positive reactions to Leprosin A after challenge with small doses of leprosy bacilli. Observations in animals of a relationship between M. leprae and M. vaccae have also been made by Watson et al. (1979). Among groups of people, mean positive reaction sizes may be of importance. Thus the children tend to produce larger-sized responses to Leprosin A than do the patients (Table 5), and the same is true of Vaccin. The reverse is the case for Marinin prepared from $M$. marinum, an organism apparently frequently met by patients and children. The results of lymphocyte transformation tests with Leprosin A (Figure 2) do not correlate with the skin-test results. Although they show some differences between the children and lepromatous patients. Of the 23 children tested, 3 show markedly greater transformation than the others. Transformation in the presence of Vaccin produced results remarkably similar to those with Leprosin A and the highest results occur in the same 3 children. 


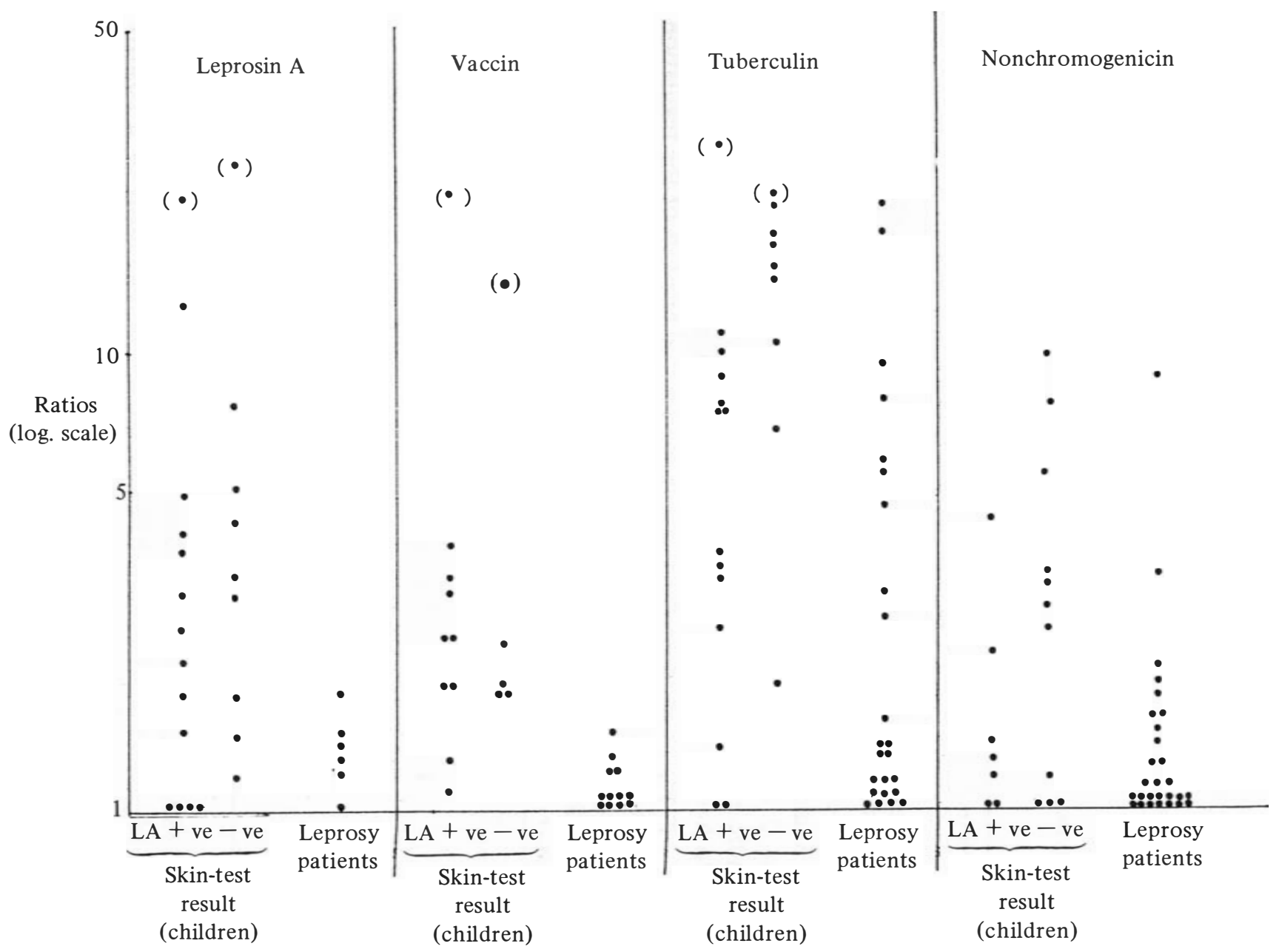

Figure 2. Lymphocyte transformation test results. 


\section{$312 J$ L Stanford et al.}

Table 5. Mean positive reaction sizes $(2 \mathrm{~mm}$ or more induration at 72 hours $)$ of leprosy patients and their BCG-vaccinated children to 5 skin-test reagents. Statistical significance for the different reaction sizes between the patients and the children has been calculated by Student's t test. Numbers of positive reactors are shown in parentheses

\begin{tabular}{|c|c|c|c|}
\hline \multirow[b]{2}{*}{ Reagent } & \multicolumn{2}{|c|}{ Mean positive reaction sizes } & \multirow[b]{2}{*}{ Significance ( $\mathrm{t}$ test) } \\
\hline & Patients & $\mathrm{BCG}+$ ve children & \\
\hline Leprosin A & $11.67 \mathrm{~mm}(18)$ & $13.53 \mathrm{~mm}(70)$ & $P<0.08$ \\
\hline Vaccin & $5.3 \mathrm{~mm}(7)$ & $8.33 \mathrm{~mm}(16)$ & $P<0.03$ \\
\hline Nonchromogenicin & $10.12 \mathrm{~mm}(17)$ & $10.0 \mathrm{~mm}(16)$ & ns \\
\hline Scrofulin & $11.8 \mathrm{~mm} \mathrm{(21)}$ & $11.8 \mathrm{~mm}(12)$ & ns \\
\hline Marinin & $16.3 \mathrm{~mm}(26)$ & 12.7 mm (19) & $P<0.004$ \\
\hline
\end{tabular}

$\mathrm{BCG}+$ ve refers to children who have been vaccinated with BCG.

Nonchromogenicin and Tuberculin induced a considerable amount of transformation amongst some of the lepromatous patients and did not discriminate between any of the groups. The 3 children producing the highest results with Leprosin A and Vaccin were not tested with Nonchromogenicin, but with Tuberculin, 2 of the 3 produced the highest results of their groups. Our results do not indicate that lymphocyte transformation tests of the type described here would have any value as a measure of protection. However, recent studies (Bahr et al., in preparation) suggest that more detailed analysis of the regulation of such lymphoproliferative responses may provide valuable information.

Table 6. The results of ELISA of immunoglobulin to the antigens of 4 mycobacterial species. The results are expressed as absorbance values

\begin{tabular}{|c|c|c|c|c|}
\hline & M. leprae & M. vaccae & M. nonchromogenicin & M. tuberculosis \\
\hline \multirow[t]{2}{*}{ Patients } & 0.29 & 1.93 & {$[0.189$} & 0427 \\
\hline & $P<0.0001$ & $P<0.0001$ & $P=0.004$ & \\
\hline \multirow[t]{2}{*}{$\begin{array}{l}\text { Leprosin A + ve } \\
\text { children }\end{array}$} & {$\left[\begin{array}{lll}0 & 07\end{array}\right]$} & 059 & 0.247 & 0.33 \\
\hline & $P=0.1$ & & $P=0.0002$ & $P=0.002$ \\
\hline $\begin{array}{l}\text { Leprosin A - ve } \\
\text { children }\end{array}$ & \lfloor & 6.65 & {$[0.087]$} & $0.18^{ل}$ \\
\hline
\end{tabular}

The ELISA results (Table 6) again pointed to a relationship between $M$. leprae and $M$. vaccae, and also indicated that the development of a positive leprosin A response is not associated with an increased level of antibody against these organisms. Skin-test positivity may even be associated with lower levels of antibody to $M$. leprae and related species, in which case measurement of antibody to selected antigenic components may prove to be of value in the future.

The lack of development of overt leprosy lesions in these children with 
considerable exposure to $M$. leprae over their entire lifetimes provides evidence of their lack of susceptibility to the disease. Thus the observations made are likely to reflect the immunological status of the protected individual. Probably the 2 or 3 children differing from the others have recently undergone or are presently experiencing some mycobacterial challenge. Whether they will successfully overcome it and their immunological parameters return to that of their fellows, and whether their fellows will in turn experience similar immunological disturbances we hope to discover by retesting the same individuals over a number of years.

\section{Acknowledgements}

We would like to thank the Iranian Leprosy Association, Lepra and the British Council for their financial support of the project. Much of the basic research in London has been supported by the Immunology of Leprosy (IMMLEP) component of the UNDP/World Bank/WHO Special Programme for Research and Training in Tropical Diseases. The views expressed in this paper are not necessarily those of our sponsors.

\section{References}

Bahr GM and others (in preparation).

Paul RC, Stanford JL, Carswell (1975) Multiple skin-testing in leprosy. J. Hygiene (Camb), 75, 57-68.

Rook GAW, Stanford JL (in preparation).

Shepard CC, Draper P, Rees RJW, Lowe C. (1980) Effect of purification steps on the immunogencity of Mycobacterium leprae. British Journal of Experimental Pathology (in press).

Shield MJ, Stanford JL, Paul RC, Carswell (1977) Multiple skin-testing of tuberculosis patients with a range of new tuberculins, and a comparison with leprosy and $\mathrm{Myco}$ bacterium ulcerans infection. J. Hygiene (Camb), 78, 331-48.

Stanford JL, Rook GAW, Convit J, Godal T, Kronvall G, Rees RJW, Walsh GP (1975) Preliminary taxonomic studies on the leprosy bacillus. Br J exp Path, 56, 579-85.

Stanford JL, Shield MJ, Paul RC, Khalil A, Tobgi RS, Wallace A (1976) The effect of desert conditions on the reactivity of Libyan schoolchildren to a range of new tuberculin. J. Hygiene (Camb), 77, 63-75.

Stanford JL, Shield MJ, Rook GAW (1978) Mycobacterium leprae, other mycobacteria and a possible vaccine. Proceedings of the XI International Leprosy Congress, Mexico City, November 1978, pp. 102-7, (International Congress Series No. 466, Leprosy). Holland: Excerpta Medica.

Stanford JL, Shield MJ, Rook GAW (1980) An investigation of a range of new tuberculins, the epidemiological factors that influence them and their value in elucidating the nature of the immunological spectrum of the mycobacterioses. Bull. International Union Against Tuberculosis (in press). 
Voller A, Bidwell DE, Bartlett A (1979) Enzyme-linked Immunosorbent Assay - A Guide With Abstracts of Microplate Applications. Guernsey: Dynatech-Europe.

Watson SR, Morrison NE, Collins FM (1979) Delayed hypersensitivity responses in mice and guinea-pigs to Mycobacterium leprae, $M$. vaccae and $M$. nonchromogenicum cytoplasmic proteins. Infection and Immunity, 25, 229-36. 